\title{
Vestígios do topos do panegírico na poesia de Geraldo Carneiro
}

A Toposforschung (investigação do topos), tal como fixada por Ernst Robert Curtius em seu Literatura europeia e Idade Média latina (1979), não apenas admite como está condicionada ao problema da tradição literária, a partir do qual o estabelecimento da genealogia de um topos (surgimento, recepção, formas de apropriação e variações) confunde-se com a identificação dos elos de uma cadeia cultural presente e ativa dentro da literatura de uma determinada época.

Do pressuposto de que a presença de certos topoi poéticos indicia uma transmissão de tradição literária entre um e outro contexto, decorre uma segunda noção, tão importante quanto a primeira, que é a de unidade cultural, corolário da investigação tópica consagrada por Curtius. Assim, o trabalho do erudito alemão teria como propósito último atestar uma unidade cultural europeia, cujo momento inicial seria a cultura greco-latina, posteriormente assimilada pelo medievo e repassada, finalmente, para as literaturas europeias nacionais.

Fora desses dois postulados - o da tradição e o da unidade literária -, o método da investigação tópica seria, em tese, impraticável, sobretudo se se toma como material de trabalho um corpus lírico produzido no contexto da contemporaneidade. O problema não estaria, propriamente, no estudo da atualização de um topos (o carpe diem, o exegi monumentum, o florebat olim etc.) em um poema do século XXI, mas, sim, na impossibilidade de acatá-lo como um indício de uma unidade literária com a cultura à qual o poema faz referência.

A deposição dos fundamentos da tradição clássica iniciada pelo movimento romântico, seguida das experiências de ruptura praticadas pelos modernismos do século XX, impôs uma evidente e profunda cisão no processo de transmissão das convenções da lírica tradicional, entre as quais os chamados lugares-comuns ou topoi. Por essa razão, aqueles

\footnotetext{
${ }^{1}$ Doutor em letras e professor da Universidade Federal do Espírito Santo (Ufes), Vitória, ES, Brasil. E-mail: paulorsodre8@gmail.com

${ }^{2}$ Doutor em letras e professor da Universidade Federal do Maranhão (UFMA), São Luís, MA, Brasil. E-mail: rafaelquevedo2001@ yahoo.com.br
} 
dois postulados distintivos da investigação tópica de cunho filológico deixam de ser pertinentes quando o corpus em estudo pertence a uma produção contemporânea. Forçoso é, portanto, que seja de outra ordem a angulação que deve ser feita pelo estudioso que se interesse em tratar do problema da tópica em poemas contemporâneos.

Evidentemente, ao cultivar um topos tradicional em seu poema, um poeta atual não o faz por um "dever de ofício", desvinculado que está de uma conjuntura cuja vigência do princípio da imitatio, de extração clássica, induzia o autor ao compromisso de exibir sua filiação a antecessores com os quais sua obra mantinha uma relação de reverência. Nesse sentido, ao incorrer no emprego de um dado esquema de conteúdo ou mesmo em fórmulas de expressão já catalogadas no acervo da lírica tradicional, outros são os problemas que um poeta do século XXI mobiliza, em vez daqueles que dizem respeito à unidade cultural e à continuidade da tradição.

Das questões suscitadas pela investigação tópica em um corpus contemporâneo, as mais instigantes são as decorrentes dos "deslizes" de sentido, os quais advêm, por sua vez, do próprio deslocamento temporal intrínseco ao exercício de quem resgata um molde antigo e o remodela em um quadrante temporal diverso. Mais que fazer falar a tradição num diapasão atual, um poema moderno que resgata um antigo topos (como é o caso do poema de Geraldo Carneiro a ser analisado neste artigo) pode fazer falar o próprio contemporâneo na clave anacrônica em que é vazado. Cabe ao crítico, portanto, desdobrar ainda mais as possibilidades resultantes do exercício "anacrônico" praticado pelo poeta. Nesse sentido, o que aqui se propõe é, à sua maneira, um trabalho também de compreensão do contemporâneo, gesto de algum modo inspirado no famoso ensaio de Giorgio Agamben, especialmente quando este afirma que:

Pertence realmente ao seu tempo, é verdadeiramente contemporâneo aquele que não coincide perfeitamente com este, nem está adequado às suas pretensões e é, portanto, nesse sentido, inatual; mas, exatamente por isso, exatamente através desse deslocamento e desse anacronismo, ele é capaz mais do que os outros, de perceber e de apreender o seu tempo (Agamben, 2009, p. 58-59). 
Cabem, ainda, algumas breves considerações de âmbito metodológico antes de entrarmos no comentário acerca do poema de Carneiro.

"a ideia da mulher", poema objeto de discussão deste artigo, não é um caso "acidental" dentro da contemporânea produção lírica brasileira, muito embora não seja uma prática recorrente a retomada deliberada de topoi poéticos de procedência clássica ou mesmo medieval. Autores como Nelson Ascher (2005), Érico Nogueira (2010) e Paulo Henriques Britto (2012) são alguns dos poetas que se dedicaram a esse exercício. Contudo, casos há em que vestígios tópicos (o uso de certas imagens, alguma fórmula linguística típica etc.) insinuam-se por entre os versos, sem que haja indícios contundentes de que o poema, efetiva e deliberadamente, resgate determinado lugar-comum consagrado ou reverencie a autoridade da tradição clássica ou medieval.

Nesse caso, existe a possibilidade de se tratar de uma "topada" no topos, a saber, o caso, totalmente factível, de um poema enveredar por um veio temático e acabar por incorrer em certas convenções já estocadas. ${ }^{3}$ Para o estudioso assentado sobre as bases da Toposforschung levada a cabo por Curtius, tal possibilidade encobriria um risco contra o qual a investigação precisaria se precaver, qual seja, o de julgar como "continuidade histórica do tópico" um caso de "poligenesia literária", como observou Segismundo Spina acerca da análise feita por Curtius do tópico do "mundo às avessas":

o exame da reprodução tópica pode conduzir-nos à errônea suposição de que se trata de uma continuidade histórica do tópico, quando muitas vezes pode acontecer que se trata de casos de poligenesia literária. Alhures já estudamos o tópico do "mundo subvertido", em que procuramos mostrar que Curtius deve ter feito confusão quando misturou nesse outros tópicos, como o do florebat olim [...] e o da seriação de impossibilia (adynata) (Spina, 2013, p. 19).

Ora, para a readequação metodológica aqui proposta, tal risco se relativiza bastante (ou, até mesmo, deixa de existir), na medida em que estaria fora do escopo do investigador a tarefa de estabelecer os rastros de uma continuidade histórica que, em última instância, pudessem

\footnotetext{
${ }^{3} \mathrm{O}$ jogo de palavras topos/topada foi tomado de um poema de Affonso de Romano de Sant'anna presente no livro Intervalo amoroso e outros poemas escolhidos, mais precisamente da seguinte estrofe: "Forma melhor de escrever é ler e ler nos outros/o que pensamos ser só nosso e é de tantos, há tanto,/que nada de novo existe, topos com que topo eu,/lugar-comum de tantos tipos que me reescreveram" (Sant'Anna, 1999, p. 107).
} 
atestar uma unidade cultural ou literária. Assim, a dúvida sobre se a presença de um tópico em determinado poema adviria de uma deliberada escolha do autor a partir do acervo fornecido pela tradição ou se circunstâncias históricas semelhantes teriam engendrado esquemas de expressão similares só amplia, ainda mais, o espectro de possibilidades em torno dos problemas pertinentes à relação da poesia contemporânea com a tradição e desta, por sua vez, com seus respectivos contextos de produção.

\section{"a ideia da mulher"}

Chama a atenção de um leitor contemporâneo um título como "a ideia da mulher", publicado em 2006 no livro Balada do impostor, de Geraldo Carneiro. Principalmente pelo fato de, nesses últimos anos, ser difícil se arriscar a ter "ideia" de uma figura tão desvelada e problematizada em termos literários, teóricos e críticos desde fins da década de 1960, quando as próprias mulheres, mas não só, passaram obstinadamente a discutir o que seria essa "ideia" em vários níveis das ciências humanas. Surpreendem ainda mais as imagens desse poema que, num mosaico desconcertante, parece flagrar não "a" mas "uma" ideia polêmica de mulher.

mulher é uma aventura que despenca

do céu e ganha a configuração

de um ser a quem devemos adorar

por alucinação ou lucidez.

alguma luz que desce lá do empíreo

se encarna aqui no inferno-céu

e se apaga ou desesplende

instaura uma aura-dor ao seu redor

e sendo sempre pássara passageira

voa em direção ao firmamento

desaparece na moldura do horizonte

e nada mais é firme

e nada é certo

a não ser a certeza de sua ausência (Carneiro, 2006, p. 64).

Numa primeira visada do poema, observa-se que o conjunto dos termos empregados pelo poeta para a composição da ideia de mulher ("céu", "empíreo", "aura", "pássara", "voa", "horizonte") resulta em 
geral abstratizante. Além de termos de sentido aéreo, reforçadores do que foi indicado pelo título, o poema aparenta ser inicialmente destituído de convenção poética. Contudo, sua forma parece ser arrumada nos 14 versos de um soneto de versos brancos - mas com sonoridades próximas ou rimas internas no quarto ("por alucinação ou lucidez"), oitavo ("instaura uma aura-dor ao seu redor") e nono ("e sendo sempre pássara passageira") versos, comuns na poética de Geraldo Carneiro - e livres, exceto nos cinco primeiros, no oitavo e no último, decassílabos heroicos. Não se pode ignorar, ainda, que esse poema se insere na terceira parte do livro, ${ }^{4}$ intitulada "a invenção da rosa", em que a ponderação sobre o sentido das coisas permeia os poemas.

Desde ao menos Helena de Troia, os poetas - incluindo Safo - são obsidiados pela imagem feminina. Escusando-nos de rastrear o histórico diversificado e complexo dessa imagem, interessa-nos, neste comentário crítico, investigar o traço tópico na composição dessa espécie de "soneto" de Geraldo Carneiro, em que se insinua uma estranha retomada de um tópico que os trovadores glosaram exaustivamente nas cantigas amorosas: o panegírico ou o elogio da mulher, "o aspecto mais rico de motivos e clichês da poesia trovadoresca luso-galega. O elogio obedece a uma gradação, partindo da sua forma mais simples - que são as expressões de tratamento -, até à forma superlativa - a do panegírico impossível" (Spina, 2009 , p. 111). A beleza da mulher amada pauta-se, em geral, em sua origem divina, de que é exemplo a clássica cantiga "Quer'eu em maneira de proençal", de Dom Dinis, em que o elogio da dama segue como razon ou assunto central na composição de um cantar nos moldes provençais:

Quer'eu em maneira de proençal fazer agora um cantar d'amor, e querrei muit' i loar mha senhor a que prez nem fremosura nom fal, nem bondade; e mais vos direi em: tanto a fez Deus comprida de bem que mais que todas las do mundo val.

Ca mha senhor quizo Deus fazer tal, quando a fez, que a fez sabedor de todo bem e de mui gram valor,

${ }^{4}$ Quatro partes compõem o livro: "Orfeu contra Odisseu”, "rejubilac", "a invenção da rosa" e "juízo final". 
e com tod' est'[o] é mui comunal ali u deve; er deu-lhi bom sem, e desi nom lhi fez pouco de bem quando nom quis que lh'outra foss'igual.

Ca em mha senhor nunca Deus pos mal, Mais pos i prez e beldad' e loor [...] (Mongelli, 2009, p. 66).

Todos os atributos femininos - morais ("prez", "bondade", "comprida de bem", "comunal") e físicos ("fremosura", "beldad") - derivam de uma vontade expressa de Deus ("Ca mha senhor quizo Deus fazer tal"; "Ca em mha senhor nunca Deus pos mal"). Criatura divina, a "senhor" "mais que todas las do mundo val", o que a torna ímpar ("quando nom quis que lh'outra foss'igual"). Com poucas variações, o elogio trovadoresco expresso nas cantigas de amor é o mote a ser observado no poema de Carneiro.

Os quatro primeiros versos (e essa marcação de quarteto é perceptível pelo único ponto do poema: "por alucinação ou lucidez") abordam metaforicamente a "origem" da mulher. Como aventura, a mulher é conceituada, mas uma aventura que despenca do céu. Um dos termos mais caros à ficção medieval, expressa nos romances corteses e nas novelas de cavalaria, "aventura" implica o sentido de seu termo inicial ventura, isto é, "fado, destino, sorte, fortuna" (Cunha, 1994, p. 815). Por essa razão, os derivados lexicais como aventura acabam por abranger sentidos como o de "feito de arma, sucesso estranho, caso fortuito, acaso", ou ainda "sucesso notável ou famoso" (Magne, 1967, p. 176-177) ou, mais modernamente, "circunstância ou lance acidental, inesperado", "empresa de desfecho incerto", "eventualidade", "o que vai acontecer" (Houaiss e Villar, 2001, p. 356). Em comum essas acepções têm o fato de se submeterem à noção de imprevisibilidade: uma aventura que despenca do alto.

Antônio Geraldo da Cunha auxilia na compreensão etimológica, ainda que obscura, do termo: "penca: conjunto ou esgalho de flores ou frutos" (1994, p. 592), de modo que o verbo "despencar" significa, por conseguinte, "soltar(-se) da penca, do cacho (esp. banana) [...], arrancar [...] tombar [...] atirar-se [...] aparecer [...]" (Houaiss, 2001, p. 1.010). Embora o verbo não tenha necessariamente um sentido cômico ou humorado, em geral e no caso específico do verso de Carneiro, este é quase sempre inevitável, dado o tom constantemente irônico do poeta em seus textos. De todo modo, "Despencar do céu" significaria 
simbolicamente que a mulher, parte do conjunto ou esgalho de astros e luzes celestes, despenca-se e cai. Nesse sentido, a imagem insinua um rebaixamento, já que se trata de uma "aventura" que descende, que se configura num ser a quem, a despeito de ter perdido seu lugar alto de origem, "devemos adorar/por alucinação ou lucidez".

Esses três termos dimensionam o sentido de "despencar do céu". O verbo adorar, que abrange o amor místico e o amor extremo, a veneração (Cunha, 1994, p. 16), é contornado pelo motivo dessa ação: por alucinação, cujo sentido é o de perceber o inexistente, erro mental na percepção dos sentidos (Houaiss, 2001, p. 171); ou por lucidez, que implica o oposto da alucinação, da loucura, ou seja, "capacidade de conhecer, compreender e aprender" (Houaiss, 2001, p. 1.788). Diante desses efeitos contraditórios, a ideia de mulher é realçada como a de um ser adorável, restrito a um culto derivado do delírio ou da consciência de sua aparição despencada de qualquer lugar que escapa aos quadrantes do mundo material.

Note-se que o sujeito lírico, subentendido nos versos iniciais, explicita-se na primeira pessoa do plural ("a quem devemos adorar"), ensejando não uma ideia particular, própria, individualizada, mas alçando-se na prerrogativa de representar a si e a um grupo de homens, de poetas, de gêneros que cultuam ou veneram essa figura feminina.

Os quatro primeiros versos, assim, tratam da manifestação da mulher e de sua transformação em objeto de culto.

O segundo conjunto de versos, a que também chamaremos quarteto se estivermos certos de que se trata de um soneto pulverizado no poema -, retoma por meio de paralelismo semântico os sentidos dos versos iniciais e os traduz: i) "mulher é uma aventura que despenca/do céu" que corresponde a "alguma luz que desce lá do empíreo"; ii) "e ganha a configuração/de um ser a quem devemos adorar" - "se encarna aqui no inferno-céu/e se apaga ou desesplende"; e iii) "por alucinação ou lucidez" - "instaura uma aura-dor ao seu redor". A mulher celeste cai no mundo-inferno, tornando-o céu (devido à presença da mulher-luz), e deve ser adorada, pois, apesar do apagamento do esplendor, dada a sua "encarnação" no mundo, ela "instaura uma aura-dor a seu redor".

Duas imagens e seus termos, no segundo quarteto, merecem comentário, dada sua relevância na tradição literária, conhecida pelo elogio à mulher e ao amor: "se encarna aqui no inferno-céu" e "aura-dor" . A "aura" compõe uma das canções mais famosas de Arnaut Daniel, 
"L'aura amara", 5 que, segundo Riquer, compreende um "verdadeiro labirinto de rimas caras em breves unidades (às vezes de uma única sílaba), o que implica uma expressão elíptica e retorcida que torna possível varias interpretações" (Riquer, 1992, p. 624, tradução nossa). Na canção de Daniel, a aura amarga significa a aragem matutina e nebulosamente fria que cala o canto dos pássaros e faz sofrer o trovador, cujo afã erótico não é atenuado pela dama. Desse modo, a "aura-dor" de Carneiro, a paixão que a mulher luminosa causa no poeta, parece corresponder por intertexto à aura amarga em que se situa e se queixa $o$ trovador sem o bem da mulher de "doce rosto".

A "encarnação" da mulher, que, no poema de Carneiro, imprevistamente despenca do céu - tornando "céu" a terra do poeta, o inferno, por meio do enamorar-se sublime -, é uma imagem que também ressoa intertextualmente uma famosa redondilha de Luís de Camões, o vilancete "Pastora da Serra", em que a beleza estelar da pastora torna céu a Serra da Estrela, espaço bucólico por excelência, onde ela vive:

Não teve esta serra

no meio da altura

mais que a fermosura

que nela [a pastora] se encerra.

Bem céu fica a terra

que tem tal estrela:

perco-me por ela (Camões, 1973, p. 6).

Ademais de tornar céu a terra do enamorado, este alucina por ela, pois "perde-se (de amor)" pela pastora da Serra, o que torna esses versos camonianos outro intertexto de Carneiro.

Voltando ao paralelismo dos dois quartetos do poema do brasileiro, "aventura" é luz; despencar é descer, configurar-se em ser é encarnação, adorar por loucura ou por sanidade é sentir o efeito da "aura-dor" que a aventura luminosa encarnada desencadeia a seu redor, a paixão.

Embora paralelísticos, os versos do segundo segmento do poema de Carneiro realçam um aspecto: não obstante a mulher, aventura de luz, apagar-se ou desesplender-se devido a sua "encarnação", ainda assim, ela instaura uma aura e uma dor. Conquanto signifique brisa, aragem, sopro (Cunha, 1994, p. 83) - e ainda que os versos de Daniel sugiram a relação de "aura" com essa acepção inicial -, tudo indica que o sentido

\footnotetext{
${ }^{5}$ Tornada famosa também pela transcriação poética de Augusto de Campos (1987, p. 88-95).
} 
"místico" de aura, isto é, um campo energético ou espiritual de que se reveste um corpo ou "suposta manifestação de substância etérea que irradia de todos os seres vivos, somente perceptível por pessoas de sensibilidade especial" (Houaiss, 2001, p. 345), seja o mais adequado para a leitura do verso, considerado o campo semântico que configura os versos iniciais: céu e empíreo.

Em seguida, o primeiro "terceto" detalha a "encarnação" da mulher-luz que se desesplende, como vimos, e se apaga ao se tornar ou se metamorfosear em "pássara". No entanto, se os verbos até essa altura estão no presente do indicativo, garantindo a nitidez do conceito que o sujeito lírico quer organizar do que seja mulher, o verso "e sendo sempre pássara passageira" coloca em gerúndio e em advérbio de tempo de continuidade perpétua ("sendo sempre") a condição dessa mulher: ela não é apenas "pássara", mas "passageira", o que realça a passagem brevíssima da mulher pelo "aqui inferno-céu", referência espacial dicotômica que situa o sujeito lírico entre dimensões inconciliáveis: inferno (mundo sem a presença aurática da mulher) e céu (mundo com a presença dessa mulher-luz). A antítese, já anunciada em termos de abstração ("céu", "luz") e de materialidade ("configuração de um ser", "encarna"), de alto ("céu", "empíreo") e de baixo ("despenca", "aqui"), de loucura ("alucinação") e de juízo ("lucidez"), ganha mais intensidade por meio da oposição entre "sempre" e "passageira", o que acentua certa dramaticidade da percepção da mulher pelo poeta.

Destacamos o substantivo "pássara", facilmente apreensível como termo nobre ligado a pássaro, ave-mulher em seu voo idealista e sublime. Entretanto, "pássara", como "despencar", pode ter sua relação com o humor, já que significa "fêmea do peru, perua", e pode ser entendido como eufemismo de vulva (Houaiss, 2001, p. 2.144). A confirmar esta última acepção, Horácio de Almeida inclui esse termo em seu Dicionário de termos eróticos e afins (1981, p. 197). Talvez seja o caso, contudo, de aceitarmos "pássara" como feminino de "pássaro", condizente com o tom mais elevado que predomina nas imagens e no pensamento do poema.

O último "terceto", negativo e/porque melancólico, expõe o efeito dessa passagem pássara e aérea da mulher: "e nada mais é firme/e nada é certo/a não ser a certeza de sua ausência". Despencada do céu, apagada pela encarnação e incapaz de pousar "aqui", a mulher não consegue ser mais que ausência na percepção do sujeito lírico, ainda que 
instaure a paixão ("aura-dor") e provoque a adoração dos que a percebem, seja por meio da alucinação, seja por meio da lucidez.

Nesse ponto, voltamos ao verso situado no que consideramos o coração do texto: "se encarna aqui no inferno-céu". Sem superinterpretar a estruturação do poema, trata-se de um verso que funcionaria como uma linha do horizonte, admitindo-se que os versos que o antecedem tratam de céu e de empíreo, e os subsequentes, do mundo físico do "aqui". No verso destacado, em especial, parece ocorrer a chave de leitura de "a ideia da mulher". Que alcance consegue ter esse advérbio "aqui", em que se fundem ou se justapõem em agonia "inferno" e "céu"? Nitidamente platônico ou neoplatônico - em última instância, extremamente idealista -, o poema expõe um conceito de mulher que, embora configurada em ser, ${ }^{6}$ não se restringe ao espaço material, porque, mesmo sendo "pássara", não pousa, não aninha, mas "voa" sempre em direção à ausência. Assim, o título do poema abrange uma reflexão do sujeito lírico sobre a imaterialidade e a inalcançabilidade da mulher, além de sua origem, mais que nobre, sublime, pois empírea. Nesse sentido, "aqui" poderia ser evidentemente interpretado como o mundo em que se situam o poeta e seus "cúmplices" de pensamento.

No entanto - e inclinamo-nos a ler por esse viés o poema de Carneiro -, "aqui" poderia ser uma referência não ao espaço externo, ao mundo frustrante do poeta e de seus sequazes idealistas, mas ao espaço mesmo do poema, da ficção lírica, lugar textual onde mais provavelmente a mulher é percebida/inventada como "aventura que despenca do céu", e reduzida ou ampliada a uma "ausência". Somente nesse "aqui", inferno-céu, é que o poeta adora, alucina ou elucida a visão da mulher, por meio de símbolos e metáforas, abstraindo-a de tal modo que nada resta senão impermanência. É no poema, portanto, que a mulher perde sua individualidade, dilui-se e pulveriza-se em astro, em luz, em "pássara".

É nesse espaço verbal do poema que o poeta apresenta uma ideia de mulher. Por meio desta, sugere uma concepção de amada e, logo, de amor que, inevitavelmente - mesmo que o autor escape à "continuidade histórica do tópico" e exemplifique, na verdade, um intertexto -, enraíza-se na tópica do panegírico feminino trovadoresco, em especial o galego-português, em que a mulher é criatura de Deus (céu), como se pode observar em trechos

\footnotetext{
${ }^{6}$ Mas, note-se, não em forma de corpo feminino concreto, pois nenhum traço de sua corporeidade bela é mencionado.
} 
de diversas cantigas de amor, a exemplo da de Dom Dinis apontada anteriormente. Em outros poemas de Geraldo Carneiro, a propósito, a mesma ideia de mulher como criatura perfeita de Deus é flagrada. Em "a aquarela dela", os últimos versos afirmam: "Deus pode até ter cometido enganos / mas em você acertou todos os planos" (2006, p. 35).

Dessa maneira, a dama do poeta moderno é encarnada em beleza física e moral tão intensas, que ele não percebe outra alternativa, depois de olhá-la, senão adorá-la "por alucinação ou por lucidez", sabendo de antemão que a aura emanada dessa mulher despencada do céu nada mais fará que, "passageira", voar em direção ao firmamento, e desaparecer na "moldura do horizonte", ficando apenas com a certeza de sua ausência grafada no limite de um poema, única forma de apreendê-la.

Os 14 versos de Geraldo Carneiro glosam o panegírico da mulher amada medieval, tocando em seu cerne: por ser aventura luminosa divina, excede em beleza de tal modo que não pode mais que instaurar dor e ausência no plano da expressão literária, puro fingimento, refinada retórica.

Na memória do sistema literário, "que desempenha uma função de grande relevância no processo de comunicação literária" e "funciona como um thesaurus", "em que perduram, confluem e dialogam motivos, imagens, símbolos, temas, esquemas formais, técnicas compositivas, estilemas, etc. a cujo influxo o emissor [o autor] não se pode eximir" (Silva, 2007, p. 263), Geraldo Carneiro encontrou a tópica que lhe ensejou uma retomada polêmica de um modo de pensar a mulher.

Por um lado, pode-se considerar positivo um conceito de mulher que a sublime - tomando-a por "aventura que despenca do céu" e que, encarnada, só pode ser "pássara passageira", porque demasiadamente alta para corporificar-se em mulher "simplesmente". No entanto, por outro, esse tipo de elogio revela, na verdade, um pensamento misógino, como pensa Howard Bloch, já que sequestra à mulher sua individualidade material, sua presença de fêmea, sua subjetividade integral física e moral. Para Bloch, "misoginia seria qualquer forma de redução da mulher a afirmações generalizantes, sendo elas boas ou más, e a não percepção das mulheres como indivíduos" (1995, p. 12-13).

Assim sendo, sublimá-la ou rebaixá-la em extremos faz parte de um discurso que termina por negar-lhe a condição de indivíduo. E o sujeito lírico do poema de Carneiro é ainda mais radical que o das cantigas de amor trovadorescas: nestas o retrato ainda menciona certa corporeidade feminina, exprime ainda subjacentemente o desejo de um bem. O elogio 
de Carneiro, diferentemente, abstrai por completo a mulher, reduzindoa a uma falta incontornável. Nesse sentido - e considerando que persona lírica e autor empírico se desvinculam, como se sabe -, a esse sujeito lírico, representação de um pensamento masculino heterossexual idealista, ${ }^{7}$ é que é dada a responsabilidade de um pensamento misógino que, vigoroso ainda hoje, é por muitos francamente rejeitado.

Em Balada do impostor, percebe-se nitidamente a rede de referências, alusões e intertextos de Geraldo Carneiro produzida numa atmosfera de bom humor, de tal modo que os dramas e impasses mais sofridos são atravessados por calembur e por inversões irônicas que não permitem dúvidas sobre o distanciamento literário com que o poeta trabalha as emoções e as reflexões em seus versos. Herdeiro da coterie pessoana, Geraldo Carneiro finge e deixa ao leitor encontrar nos poemas o sentimento pensado. Nesse sentido é que Nelson Ascher parece basear sua afirmação de que o autor carioca "recoloca, com seriedade e humor, a poesia no lugar que lhe cabe" (2006), ou Silviano Santiago percebe que "O poeta sobrevive como ator numa infinita rede de falas. Melhor dizendo, como reator" (2006).

Ilustra essas observações certeiras o poema "o não decifrador", cujo sujeito lírico, composto com camadas de Orfeu, pondera:

tudo que escrevo foi talvez escrito ou sonhado por outro antes de mim.

minhas metáforas não me pertencem.

a língua me sugere seus enigmas,

o que me cabe é apenas recifrá-los

como um decifrador a quem não fosse

revelada a chave do código.

a desrazão me inspira

e ao meu redor

vou inventando o mundo em que me amparo.

me falta o credo para chamar de alma

aquilo que me anima os meus amares.

no entanto sei que há vozes aqui dentro.

sou tão medíocre quanto qualquer ser

que habite nesta esfera.

\footnotetext{
${ }^{7}$ Em que pese o fato de não haver marcas de gênero nos versos, podendo assim o "nós" do poema se referir aos homens hétero ou bissexuais ou às mulheres homo ou bissexuais.
} 
sei que o ar é raro rarefeito

feito de um sopro cuja cor me escapa

embora a flor se ofereça no meu sonho (Carneiro, 2006, p. 32).

O poema se articula a partir de um pressuposto: "no entanto sei que há vozes aqui dentro", cujo sentido, derivado dos primeiros versos ("tudo que escrevo foi talvez escrito/ou sonhado por outro antes de mim./minhas metáforas não me pertencem") converge para o conceito mais amplo de intertexto ou, se, ao contrário, quisermos especificar ainda mais esse termo, converge para o conceito de topos, uma espécie de intertexto, como tendemos a pensar, contornado pela ideia de que certos clichês, esquemas de pensar, imagens fixas e concretas, motivos ou temas se relacionam, por adesão, por homenagem ou por contraste, a tradições literárias não apenas antigas (Kayser, 1976, p. 70), como pensou Robert Ernst Curtius (1996), ou trovadorescas (Spina, 2009), mas a várias outras (Quevedo, 2014).

Diante disso, concordando com a afirmação de Segismundo Spina "o tópico pode explicar-se como mero expediente literário, recurso expressivo" (2009, p. 203) -, Geraldo Carneiro espalha por seus versos esse "recurso expressivo" literário, permitindo-nos detectar em sua poesia o vestígio tópico que remontaria, por exemplo, à literatura trovadoresca e ao panegírico, ainda que filtrado necessariamente pelas atualizações realizadas pelos poetas da extensa galeria de poéticas e de movimentos literários pós-trovadorescos, desde os humanistas do século XV aos contemporâneos, de que Geraldo Carneiro é exemplo destacado. Aceitando-se esse o argumento, o poeta brasileiro permite que o leitor transpasse a Toposforschung, sem ignorá-la, no entanto.

No caso pontual do poema "a idéia da mulher", mais que de uma atualização, talvez estejamos diante do que T. S. Elliot classifica como uma "deleitosa reconstrução arqueológica" (1989, p. 37), retomando o passado de modo estranho, pois desvinculado de uma ambiência histórica diferenciada da atual, o que explicaria, por exemplo, certa misoginia típica de um discurso trovadoresco que Geraldo Carneiro leva às últimas consequências.

\section{Referências}

AGAMBEN, Giorgio (2009). O que é o contemporâneo? e outros ensaios. Tradução de Vinícius Nicastro Honesko. Chapecó: Argos. 
ALMEIDA, Horácio de (1981). Dicionário de termos eróticos e afins. Rio de Janeiro: Civilização Brasileira.

ASCHER, Nelson (2005). Parte alguma (1997-2004). São Paulo: Cia. das Letras.

ASCHER, Nelson (2006). Orelha. In: CARNEIRO, Geraldo. Balada do impostor. Rio de Janeiro: Garamond.

BLOCH, R. Howard (1995). Misoginia medieval e a invenção do amor romântico ocidental. Tradução de Cláudia Moraes. Rio de Janeiro: Editora 34.

BRITTO, Paulo Henriques (2012). Formas do nada. São Paulo: Cia. das Letras.

CAMÕES, Luís de (1973). Rimas. Edição de Álvaro Júlio da Costa Pimpão. Coimbra: Atlântida.

CAMPOS, Augusto de (Trad.) (1987). Mais provençais. Seleção de Augusto de Campos. São Paulo: Companhia das Letras.

CARNEIRO, Geraldo (2006). Balada do impostor. Rio de Janeiro: Garamond.

CUNHA, Antônio Geraldo da (1994). Dicionário etimológico da língua portuguesa. 2. ed. rev. e acresc. Rio de Janeiro: Nova Fronteira.

CURTIUS, Ernst Robert (1979). Literatura européia e Idade Média latina. Tradução de Teodoro Cabral. 2. ed. Brasília: Instituto Nacional do Livro.

ELLIOT, Thomas Stearns (1989). Tradição e talento individual. In: ELLIOT, Thomas Stearns. Ensaios. Tradução de Ivan Junqueira. São Paulo: Art, p. 37-48.

HOUAISS, Antônio; VILLAR, Mauro de Salles (2001). Dicionário Houaiss da Lingua Portuguesa. Rio de janeiro: Objetiva.

KAYSER, Wolfgang (1976). Análise e interpretação da obra literária: introdução à ciência da literatura. 6. ed. rev. Tradução de Paulo Quintela. Coimbra: Arménio Amado.

MAGNE, Augusto (1967). Glossário da Demanda do Santo Graal. Rio de Janeiro: Instituto Nacional do Livro, $3 \mathrm{v}$.

MONGELLI, Lênia Márcia (Org.) (2009). Fremosos cantares: antologia da lírica medieval galego-portuguesa. São Paulo: Martins Fontes.

NOGUEIRA, Érico (2010). Dois. São Paulo: É Realizações.

QUEVEDO, Rafael Campos (2014). O lugar da investigação dos topoi na lírica contemporânea de língua portuguesa: considerações metodológicas. In: COLÓQUIO INTERNACIONAL DE ESTUDOS LINGUÍSTICOS E LITERÁRIOS, 3., 27 e 29 ago. 2014, Maringá. Anais... Maringá: UEM. Disponível em: <http:/ / goo.gl/Hj0REL>. Acesso em: 2 maio 2015. 
RIQUER, Martín de (1992). Los trovadores: historia literaria y textos. Barcelona: Planeta, t. 2.

SANT'ANNA, Affonso Romano de (1999). Intervalo amoroso e outros poemas escolhidos. Porto Alegre: L\&PM Pocket.

SANTIAGO, Silviano (2006). Orelha. In: CARNEIRO, Geraldo. Balada do impostor. Rio de Janeiro: Garamond.

SILVA, Vítor Manuel de Aguiar e (2007). A comunicação literária. In: SILVA, Vítor Manuel de Aguiar e. Teoria da literatura. 8. ed. Coimbra: Almedina, p. 181-338.

SPINA, Segismundo (2009). Do formalismo estético trovadoresco. São Paulo: Ateliê.

Recebido em novembro de 2015.

Aprovado em abril de 2016.

\section{resumo/abstract/resumen}

\section{Vestígios do topos do panegírico na poesia de Geraldo Carneiro}

Paulo Roberto Sodré e Rafael Campos Quevedo

Este artigo analisa o poema "a ideia da mulher", de Geraldo Carneiro, inserido em Balada do impostor (2006), procurando observar sua relação com a tópica trovadoresca do panegírico da mulher amada estudada por Segismundo Spina (2009). Procura interpretar o poema, contrastando o modo e o efeito que o aproveitamento do tópico pode acarretar na produção de versos contemporâneos baseados em temas de origem tão remota (século XIII) e de suporte ideológico tão distinto: a misoginia que atravessa o elogio idealista dos trovadores.

Palavras-chave: poesia brasileira contemporânea, a mulher na poesia contemporânea, panegírico, Geraldo Carneiro.

\section{Traces of panegyric topos in Geraldo Carneiro's poetry}

Paulo Roberto Sodré e Rafael Campos Quevedo

This article analyzes the poem "a ideia da mulher", by Geraldo Carneiro, that appears in Balada do impostor (2006), trying to observe its relation with the troubadour topic of the panegyric of the beloved woman, studied by Segismundo Spina (2009). It seeks to interpret the poem contrasting the mode and the effect that the use of the topic may have in the production of contemporary verses based on themes of such remote origin (XIII century) and of such different ideological support: the misogyny that runs through the idealistic praise of the troubadours. 
Keywords: Brazilian contemporary poetry, woman in contemporary poetry, panegyric, Geraldo Carneiro.

\section{Vestigios del topos del panegírico en la poesía de Geraldo Carneiro}

Paulo Roberto Sodré e Rafael Campos Quevedo

Este artículo analiza el poema "a ideia da mulher" de Geraldo Carneiro, inserto en Balada do impostor (2006), tratando de observar su relación con la tópica trovadoresca del panegírico de la mujer amada, estudiada por Segismundo Spina (2009). El artículo busca interpretar el poema, contrastando el modo y el efecto que el aprovechamiento del tópico puede provocar en la producción de versos contemporáneos basados en temas de origen tan remoto (siglo XIII) y de soporte ideológico tan distinto: la misoginia que permea el elogio idealista de los trovadores.

Palabras clave: poesía brasileña contemporánea, la mujer en la poesía contemporánea, panegírico, Geraldo Carneiro. 